\title{
A NEW OSTROWSKI TYPE INEQUALITY ON TIME SCALES
}

\section{GAOPENG XU AND ZHONG BO FANG}

Abstract. In this paper, by introducing a technique of parameter functions, we establish a new Ostrowski type inequality on time scales and unify corresponding continuous and discrete versions. Furthermore, some particular integral inequalities on time scales are given as special cases.

Mathematics subject classification (2010): 54C30, 26D10, 26D15.

Keywords and phrases: Ostrowski type inequality, time scales, parameter function.

\section{REFERENCES}

[1] S. S. Dragomir And Th. M. Rassias (Eds), Ostrowski type inequalities and applications in numerical integration, Kluwer Academic Publishers, Dordrecht, 2002.

[2] S. Hilger, A Makettenkalkl with application to center manifolds, Ph. D. Thesis, Universität. Würzburg, 1988.

[3] R. Agarwal, M. Bohner And A. Peterson, Inequalities on time scales: a survey, Math. Inequal. Appl., 4 (2001), 535-557.

[4] R. HILsCHER, A time scales version of a Wirtinger-type inequality and applications, Dynamic equations on time scales, J. Comput. Appl. Math., 141 (2002), 219-226.

[5] M. Bohner And T. Matthews, Ostrowski inequalities on time scales, J. Inequal. Pure Appl. Math., 9, 6 (2008), 8-10.

[6] W. J. Liu, A. Tuna And Y. Jiang, On weighted Ostrowski type, Trapezoid type, Gruss type and Ostrowski-Gruss like inequalities on time scales, Appl. Anal., 93, 3 (2014), 551-571.

[7] W. J. Liu, A. TunA AND Y. JiAnG, New weighted Ostrowski and Ostrowski-Gruss type inequalities on time scales, Annals of the Alexandru Ioan Cuza University-Mathematics, 60, 1 (2014), 57-76.

[8] W. J. LiU And A. Tuna, Diamond- $\alpha$ weighted Ostrowski type and Gruss type inequalities on time scales, Appl. Math. Comput., 270, (2015), 251-260.

[9] G. A. AnAStassiou, Representations and Ostrowski type inequalities on time scales, Comput. Math. Appl., 62, 10 (2011), 3933-3958.

[10] Q. H. Feng And F. W. Meng, Generalized Ostrowski type inequalities for multiple points on time scales involving functions of two independent variables, J. Inequal. Appl., 2012, (2012), doi:10.1186/1029-242X-2012-74, 11 pp.

[11] B. Zheng AND Q. H. Feng, Generalized $n$ dimensional Ostrowski type and Gruss type inequalities on time scales, J. Appl. Math., 2014, (2014), Art. ID 434958, 11 pp.

[12] W. J. LiU AND Q. A. NGô, A new generalization of Ostroski type inequality on time scales, An. St. Univ. Ovidius Constanta, 17, 2 (2009), 101-114.

[13] M. Bohner And A. Peterson, Dynamic Equations on Time Series, Birkhauser, Boston, 2001.

[14] M. Bohner And A. Peterson, Advances in Dynamic Equations on Time Series, Birkhauser, Boston, 2003. 